\title{
MAKING AFRICANA STUDIES MORE ENGAGING
}

Dr. Edward Kissi, Assistant Professor in the Department of Africana Studies at the University of South Florida (USF), continually found himself trying to orchestrate a student balancing act. On the one hand, he was determined that his students should develop and refine important skills, such as communications and judgment, while enrolled in his courses, which included a multi-semester sequence covering various time periods of African history and an introductory course on the Black Experience. On the other hand, he recognized that many of his students labored under obstacles that he had not had to face during his own education-such as the need to hold down a full time job while taking courses. Some even faced the demands of providing for children, often as a single parent. Was it fair to be as demanding of them as his professors had been of him?

Kissi recognized that encouraging critical thinking among students was particularly important in his field. Students entering the field of Africana studies—a field that focused on the contemporary and historical experience of individuals and groups whose roots originated in Africa—often did so with many misconceptions. If these misconceptions were to be corrected, students needed to abandon a view of the subject informed principally by emotions and take on the objective perspective of a historian. Helping students achieve such a transition was a challenging endeavor.

One promising avenue for helping his students become more sophisticated in their thinking involved harnessing the power of technology more effectively in his courses. During the previous summer, he had participated in a workshop offered by USF's Center for $21^{\text {st }}$ Century Teaching Excellence $\left(\mathrm{C}^{21} \mathrm{TE}\right)$, where he had been exposed to many examples of technology-enhanced teaching and learning. During the fall, he had already started to incorporate a few of these technologies into his courses, such as projecting a map of Africa with other large countries overlaid on top of it at the same scale to demonstrate the size of Africa and to refute the widespread notion (among entering students) that Africa was a country, and not a continent. Based on the positive reaction to his initial efforts, he wanted to expand his use of technology—-perhaps even try something more ambitious. He knew that the Center for $21^{\text {st }}$ Century

\footnotetext{
This case was prepared for the purpose of class discussion, and not to illustrate the effective or ineffective handling of an administrative or classroom situation and is copyrighted by the Informing Science Institute. Permission to make digital or paper copy of part or all of these works for personal or classroom use is granted without fee provided that the copies are not made or distributed for profit or commercial advantage AND that copies 1) bear this notice in full and 2) give the full citation on the first page. It is permissible to abstract these works so long as credit is given. To copy in all other cases or to republish or to post on a server or to redistribute to lists requires specific permission and payment of a fee. Contact Publisher@InformingScience.org to request redistribution permission.
}

Teaching Excellence included a faculty support group called the Media Innovation Team (MIT) whose mission was to assist him. What he did not know was how he should go about enlisting their services. Should he ask them for suggestions, or arrive at their door with a specific project in mind? Should he focus on small, incremental projects, or should he try for something larger, with greater potential impact? And what would the payoff be for the effort he expended, given the fact that he was not yet tenured? 


\section{Africana Studies}

The courses that Kissi was teaching were offered within the Department of Africana Studies at the University of South Florida (USF), a large Research I university that was part of the Florida State University System. USF's main campus was in Tampa Florida, about half-way up the state's west coast, which was where the department was headquartered. Administratively, the department was one of 28 within the USF College of Arts and Sciences. That college was the largest in the university, with 20052006 enrollments of roughly 14,000 (undergraduate) and 2300 (graduate) students. The college's staffing included 90 tenured/tenure-earning faculty, and around 100 non-tenure-track instructional personnel.

Within the state system, the USF Africana Studies department filled a distinct niche, described on the departmental web site as follows:

The Department Africana Studies is the only graduate department in the Florida State University System dedicated to the study of the Black/Diaspora experience. The department evolved from the African and African American Studies Program, one of the earliest programs of its type to have germinated from the energy of the Black student movement of the $1960 \mathrm{s...}$

In the mid-nineties, the Program's name was changed to Africana Studies to reflect its "Diasporan" focus and to join a nationwide trend toward changing Black Studies and AfroAmerican/African Studies departments and programs to this newer, more accurate descriptor...

In recent years, the department had experienced both growth and a change in focus-adding increased emphasis to its graduate program offerings, consistent with an overall transition being made by the university, as described below:

...from academic year 2000 to 2001 our student credit hours increased more than 50\%; we have established a Master's program which allows students to combine the usual academic Africana Studies program with a concentration of applied skills, skills that will enhance employability and professional development; and our Graduate Certificate program will allow individuals with a bachelor's degree and current graduate students to acquire a concentration in Africana Studies without having to do a separate degree. Most importantly, we have shifted the Department's academic orientation from the traditional black studies paradigm to a comparative diaspora one. We have, essentially, positioned our curriculum to contribute to the university's goal of moving from an 80:20 undergraduate-graduate ratio to a 75:25 ratio. The University expects to accomplish this change in undergraduate-graduate ratio while simultaneously increasing enrollment in both levels. The Department of Africana Studies expects to continue to mold its curriculum and practices to contribute to this goal. (Source: USF Africana Studies department web site, accessed at http://www.cas.usf.edu/africana_studies/history.html on 5/20/2006).

As of spring 2006, the USF Africana Studies department consisted of four tenured/tenure track faculty members (including Kissi), one visiting professor, one lecturer and eight adjuncts. In addition, eight other faculty members - from other departments and emeritus_-participated in departmental offerings and programs.

The departmental mission statement is presented in Exhibit 1. 


\section{Edward Kissi}

Dr. Edward Kissi was an Assistant Professor at USF. The path to Tampa had been a long one, spanning half the globe. He was born in Ghana, a West African nation with a population of about 18 million that is slightly smaller in area than the state of Oregon. The country achieved independence from the British Empire in 1957, after which it went through a succession of governments - some that were constructed along democratic lines, some that were not. By the time Kissi had become a teenager, however, the government of Ghana had come to recognize the importance of education if the nation were to develop an intellectual middle class, a prerequisite for further growth and prosperity. As a consequence, particularly talented students were provided with free access to higher education. Kissi had been the beneficiary of such an undergraduate education, graduating from the University of Ghana in 1987. His recollections of how his professors there contributed to his own intellectual development were very positive. He said:

At the University of Ghana, I had professors who insisted on two things: substance and communication. The ability to express yourself clearly and coherently on paper is very, very important if you are to get ahead in life...

Upon completing his undergraduate degree in Ghana, Kissi was able to obtain a scholarship to attend Wilfrid Laurier University, in Canada, where he received an M.A. in History in 1991. From there, he went on to Concordia University, in Montreal, Quebec, completing his PhD in History in 1997. Upon completing his doctorate, he was awarded a two-year long post-doctoral fellowship in the Genocide Studies Program at Yale University. His first full time academic assignment was at Clark University, in Massachusetts. In 2003, he joined the faculty at USF.

As a junior faculty member, Kissi was already developing a strong research track record. In addition to having published 4 refereed journal articles and 2 book chapters, he had presented at numerous conferences and had received several fellowships. Most recently, he had published a scholarly book that contrasted genocide in Ethiopia and Cambodia. Because of the progress he had made in his research, Kissi felt that he could afford to devote some time to enhancing his teaching skills.

\section{Teaching Context at USF}

In looking back on his own education, Kissi felt himself to be particularly blessed by the fact that he had always been able to pursue his education full time, supported by (relatively) generous scholarships. In this respect, he felt that he had a huge advantage over the students he was teaching at USF. He explained:

I had an opportunity to pursue my studies with no distractions. If I compare myself to my students, many of whom are working two or three jobs, I have to ask myself: where can they find the time? When they come home, exhausted, is it reasonable to expect them to read many chapters in a book that has few figures or illustrations? Unfortunately, there doesn't seem to be any way to shortcut this reading. But I wonder how flexible I need to be, and whether I should be lenient.

Kissi also found that students at USF could react very differently to him, an observation confirmed by his student evaluations. Some students obviously recognized the value of the skills that he was trying to build, and appreciated them. Others, however, viewed his emphasis on clarity of communications - both oral and written-and the demanding nature of courses in a more negative light. He stated: 
One of the challenges of focusing on improving communications is that the way we communicate is very personal. Some students may view the suggestion or encouragement to improve their communications skills as a form of personal attack. That means that critical comments need to be made very carefully.

Another challenge that Kissi faced involved the innate characteristics of the field he had chosen to teach. It would be hard to imagine more sensitive subjects.

\section{Teaching Areas}

At Clark and at USF, Kissi's teaching focus had been on courses in three areas: African history, the Black Experience and Genocide. These subjects were inherently challenging to teach for a number of reasons:

- Students often entered the courses with the perception that they knew more than they actually did

- Students often had preconceived notions about these areas that were inconsistent with historical or geographic facts

- Certain topics central to the courses—such as slavery and genocide-were extremely sensitive subjects for many students

As an example of the difficulties he faced, Kissi liked to point out that many of the students entering his Black Experience and African History undergraduate courses were convinced that Africa was a country. Aside from being incorrect, such a misconception made it hard for them to grasp the breadth of cultures, climates and political systems that made up the continent.

The courses in African history offered by the Department of Africana Studies were divided into two time periods, prior to 1850 and subsequent to 1850 . Both courses, which typically had enrollments of around 50 students each semester, covered many subjects that were potentially inflammatory. The pre-1850 class, which traced the development of African cultures from the dawn of history, considered the impact of the slave trade on many areas of Africa. The post-1850 class, on the other hand, focused on colonialism and independence movements as they evolved in the $19^{\text {th }}$ and $20^{\text {th }}$ centuries. Kissi noted that many of his students, taking a class in African history from a black professor, expected a far more one-sided treatment of racial issues than he was prepared to give. Rather than taking a particular side in debates relating to who did right and who did wrong, he chose to emphasize the accumulation of evidence, in the form of historical facts, and the objective analysis of these facts. Not only were these the heart of the historian's craft, the process was central to the development of student critical thinking skills. Developing these skills, in turn, was central to the department's mission (see Exhibit 1).

Kissi's course on the Black Experience, which had undergraduate enrollments in excess of 100, addressed the experiences of peoples of African descent throughout the contemporary world. As an example of the benefits of such a course, he stated:

Suppose you go on to be a doctor. Further suppose you are then posted to the Caribbean or a specific region of Africa. If you are going to be effective, you need to understand the health issues associated with the culture you are working in. You also need to understand their attitudes toward you and western medicine. Students taking this course should learn to appreciate the tremendous diversity in the worldwide African community. Doing so will broaden their intellectual horizons. 
The third area of Kissi's teaching was genocide- the central focus of his research efforts. His particular interest was on the comparative study of different genocide events across the globe. In his books and articles, for example, he had contrasted the genocide in Ethiopia with what had happened in Cambodia, in the Nazi holocaust, and in Rwanda. Although an extremely disturbing subject for most students, he focused on helping them to develop the dispassionate historian's perspective on the subject. Naturally, it was neither possible nor desirable to eliminate all the emotions associated with such incidents. If they were to be prevented in the future, however, understanding similarities and differences in their underlying causes would be critical.

\section{Teaching Approaches}

Since both his personal goals and the department's goals emphasized developing critical thinking skills in addition to conveying factual knowledge, Kissi's teaching approach did not rely exclusively on lecturing. Instead, he preferred a mix of lectures and breaking the class into small groups, for discussion. Generally the lecture to discussion ratio ranged from 1:1 to 2:1, depending upon the subject matter. During lectures, he focused on conveying facts and knowledge, a prerequisite for any understanding of history. The discussions, in contrast, were designed to serve three purposes: to help students develop their analytical skills, to help them sharpen their communications skills and to help him assess their overall level of understanding, and what needed to be worked on.

Recognizing how overcommitted many of his students were, Kissi spent a great deal of time preparing his courses. He described the process as follows:

I try to shoulder about $70 \%$ of the responsibility for the classroom. What do I mean by that? I construct a course outline that is very clear. Before I tell students to read the books, I read the books very thoroughly...Then I look at the number of days available, and select 5 to 7 themes that I am going to cover, allocating about 3 days to each theme. My idea here is that by the time three days have past, students should have learned something.

Normally, I make the first two days [of each topic] a lecture. What I want to do here is simplify the complexity of the topic. That way, a student who comes home at 11 at night after a day of work may not have to read the whole chapter. If he or she has been to my lecture, certain topics will have been covered, and they can be skipped or skimmed. I do this for the students as a means of meeting them half way, because - unlike me - they do not have the liberty to spend all their time studying because they have to work so hard...

Because I don't want to dominate the classroom, I allocate a day (maybe 2, if I only have a day of lecture) for discussion. Doing this, I can get a better understanding of how well the students understand the material we have covered... What I do is to divide the students into small groups and I ask them to come to a conclusion on the topic we have discussed.

I do this all in the name of two objectives: to inform students and to inspire students. If I do this, students, upon leaving the class, will be able engage in an intelligent conversation about Africa and can spread that knowledge throughout their communities.

Excerpts a spring 2006 syllabus are presented as Exhibit 2.

\section{Exploring Technology}


Kissi's large enrollments and sensitive material created a challenging teaching situation. Although he had not relied on technology much in his own education, Kissi was very receptive towards using technologies in his teaching-provided they met the objectives of informing and inspiring students!

One of the first steps he took towards learning how technology could be applied in his classroom was to enroll in the USF Center for $21^{\text {st }}$ Century Teaching Excellence $\left(\mathrm{C}^{21} \mathrm{TE}\right)$ Increments and Transformations Institute (ITI), beginning in the summer of 2005. The ITI was a year long program that began with a summer workshop featuring case discussions and technology demonstrations and training. This was followed by a semester during which each participant was expected to implement at least one technologybased change to a course. The final semester of the initial institute phases-the spring semesterinvolved sharing experiences with departmental and institute colleagues.

Kissi had observed many technologies that could have potential relevance for his courses. Some examples of these included:

- Audience response systems, might be used to poll students on sensitive issues (which abounded in his courses), and allow results to be displayed immediately. They might also be used to ascertain where students stood in terms of their knowledge of the readings, using short multiple choice assessments.

- Online discussions, conducted synchronously (using Elluminate) or asynchronously (using Blackboard discussion groups) might be used to encourage student engagement and to give them the opportunity to practice their communications skills.

- Multimedia content, created using tools such as Techsmith's Camtasia and digital cameras, could be used to create in-class demonstrations and content to be viewed outside of class.

- Web-based interactive content, allowing students to test their own knowledge, could be developed using tools such as Hot Potatoes or Soft Chalk.

- Student feedback could be gathered, in real time, using tools such as Flashlight Online or Survey Monkey, to allow adjustments to a course to be made before the semester had ended and it was too late.

Having seen all these tools in action, Kissi felt that each had its merits and could potentially be applied in his classes. Since he was not a "power user" of technology, however, he felt it best to begin with more modest changes. During the fall, he began to use tools such as PowerPoint and Hot Potatoes to add more visual impact to his classroom presentations. One of his favorite slides, for example, addressed the size of Africa by overlaying other countries on its outline. It graphically demonstrated that the U.S., China, India, Argentina and all of Europe could be placed in Africa, with room to spare. Once a student had seen that map, there could be no question that Africa was truly a continent.

Kissi was pleased with the initial changes that he had made to the course after coming out of the workshop. As a non-technologist, however, he was a bit bewildered regarding what to do as a next step. He knew that the Center for $21^{\text {st }}$ Century Teaching Excellence included a faculty support group called the Media Innovation Team (MIT), whose purpose was to help faculty members develop technology-based enhancements to their teaching. He already was aware of a colleague in Africana studies who was working with the MIT to develop a virtual model of a Middle Passage slave ship that had recently been found off the coast of Florida. What he wondered was if he might now be ready to engage in some similar project and, if so, what such a project might be. 


\section{USF Media Innovation Team}

The Media Innovation Team (MIT), part of the USF $\mathrm{C}^{21} \mathrm{TE}$, consisted of ten full time employees, including instructional designers, multimedia specialists, web course developers, and video production experts. Side-by-side with faculty and community-based clients, the MIT staff worked to design and implement solutions involving the integration of technology in teaching and learning.

The Team Leader for the Media Innovation Team, also the Associate Director of the $\mathrm{C}^{21} \mathrm{TE}$, was William Patterson. Prior to joining USF in 1997, Patterson had worked in faculty development at the University of Central Florida for 5 years and was responsible for the design and facilitation of over 50 different faculty workshops.

One of the Media Innovation Team's most common services was Blackboard course support. At the time of the case, the MIT annually provided over 400 Blackboard course sites with varying levels of faculty support and had been able to support $100 \%$ of the faculty requesting help with their Blackboard needs. The MIT's Blackboard support activities included a long list of services:

- Technical support for Blackboard's features

- Assistance in setting up a grade book or placing grading criteria in the Blackboard context

- Posting a syllabus

- Assistance making a syllabus more interactive and web-enabled

- Loading quizzes and establishing settings within Blackboard for various quiz parameters

- Uploading content, such as PowerPoint presentations

In addition, they also developed animations and graphics to enhance an instructor's Blackboard course site.

Although assisting with Blackboard course sites was one of the most widely used MIT services, it was not the service that consumed the majority of the MIT's time. The most time intensive activities were in the design and production areas. Through the lens of pedagogical enhancement and the critical focus of instructional design, the MIT engaged in multimedia production, video production, creation of web applications, and DVD authoring. All these services were free to the faculty (provided they involved a specific credit course they were teaching). Fee-based services were also available for non-course related content, such as creating a world class, cutting edge multimedia supplement for a new textbook authored by a USF faculty member. These fees served to stretch the MIT's budget, allowing the group to hire more faculty support personnel and to expand their faculty course support in step with the ever-changing $21^{\text {st }}$ century higher education landscape.

Providing collaborative instructional design and production assistance for a course could be an extremely time consuming process. As a result, relatively few projects, (designated by the MIT as "key projects”), could be undertaken at any given time by the group. A single key project could last months, or even years. Typically, the MIT might complete 10 such time-intensive projects in a given year; such projects accounted for up to $50 \%$ of the team's resources.

Key projects selected by the MIT generally had to meet at least two important criteria. First, they had to be of substantial prospective educational impact for a course, department, college, or to the university community. For example, if the course involved was a required undergraduate course for the College of Business, then enrollments might top 2000 students per year. By virtue of these numbers alone, such a 
course would be important to the college and the university. A course might also be important by virtue of its visibility or long term potential. A graduate course that was a pilot course for a new program (e.g., a distance learning version of a master's degree) might qualify in this respect. The second criterion was potential relevance to other courses that might need MIT support in the future. For example, one project the group worked on was a "Question of the Day" module that presented a different daily question of significant educational merit to students in the College of Engineering. The attractiveness of this project was its cross disciplinary appeal. The same module could easily be adapted to ask math questions, history questions, nursing questions, etc.

The MIT group had generally been able to support the majority of course enhancement project ideas proposed by faculty members. A somewhat organic workflow balance had been cultivated through formal print and electronic promotion, as well as word-of-mouth advertising of MIT services. Patterson did, however, have some concerns that the team might some day be swamped with requests as $21^{\text {st }}$ century faculty technology support needs continued to burgeon.

Faculty members utilizing MIT services commonly did so in phases. Patterson likened the process to a series of layers, leading to what he called the "(Patterson) Progressive Pyramid". The first, or bottom, layer of his pyramid was faculty attending workshops. These workshops provided basic training on key technologies and were available to instructors and teaching assistants at no cost. Each semester, a schedule of these workshops - typically lasting 2-3 hours - was published and distributed to faculty members. The schedule also listed non-technology focused teaching and learning workshops offered by the $\mathrm{C}^{21} \mathrm{TE}$.

By attending workshops, instructors gained a sense of the capabilities of the technologies supported by the university. This set the stage for the second phase, where faculty developed initial mastery as well as an ongoing sense of technology-related time management. At the second level faculty also began to think creatively about applying the technologies to their own classes. This might spur them to visit the MIT to collaboratively discuss and gradually flesh out their nascent ideas for enhancing teaching and learning. Patterson was careful to note that faculty members were always welcome to call and schedule such an exploratory meeting with the $\mathrm{C}^{21} \mathrm{TE}$-MIT_-attending a workshop was not a prerequisite. It just happened that workshop participants more commonly approached them.

The second layer commenced once the faculty member identified some unique idea for incorporating technology into his or her classes. The litmus test for such an idea was simple: "What could I do using this technological advancement that I couldn't do (as well) any other way?” For example, one such idea involved having the MIT create a 3D computer simulation model of a sunken slave ship that was currently in the process of being raised off the Florida coast by the Mel Fischer salvage group. The simulation would give students an opportunity to actually explore the ship in a virtual walkthrough. How could such a resource be implemented without technology, especially when the ship was still below water?

The third layer was the prototype layer. This layer could also be called the inventive stage. It was during this layer that the unique idea, initially conceived in the second layer began to take the shape of an emerging instructional artifact. This was the layer where actual production work began.

The highest layer of the pyramid, or the fourth layer, was the finished product layer. This was reached when the final product was completed and launched. Although not a requirement, some products reached this layer when they became commercially viable (e.g., when a new companion DVD-ROM, developed by the MIT and featuring a USF faculty member, was launched by a major textbook publisher along with a new cutting-edge textbook). 
It was neither required, nor expected, that all faculty members would reach the highest level of the pyramid. In fact, many faculty members decided not to go beyond the first or second layer.

\section{The Next Stage}

To Kissi, the opportunity to enlist the aid of the MIT in support of his teaching efforts seemed too good to miss. He realized, however, that if he were to make effective use of their support, he would need to have a better idea of what he wanted to accomplish. With respect to his courses, he already knew some of the most challenging aspects of the material he taught. For example:

- Helping students acquire a deep understanding of the breadth of the African continent. Beyond its physical size, which he was already demonstrating with his map, he wanted to convey a sense of just how many cultures, languages and communities made up the "African Experience”. Simple words in a textbook did not seem to be enough.

- He wanted to help his students to acquire the thought processes of historians. They needed to learn to think critically, refine their opinions with evidence and rise above purely emotional responses to the material being presented. A colleague has shown him a site, based upon Plimoth Plantation - where the pilgrims first settled - that aspired to introduce younger students to the historian's craft. Could the same type of interactive web site, tailored to the needs of his students, be developed by MIT?

- He was wondering if technology could be harnessed to help him in presenting comparative analysis. Here, his particular interest was for his course in genocide. Was there some way that he could allow students to compare different genocide events side-by-side, to see how they were similar and how they were different? It has been pointed out to him that such comparison features were frequently supported by commercial web sites. Online stores, for example, allowed shoppers to do side-by-side comparisons of complex products, such as laptop computers or automobiles. Could such technologies be adapted to the purpose of making historical comparisons?

- Were technologies available that could be harnessed to make his classroom more interactive and exciting for his students? He was pleased with the results he had achieved through the use of PowerPoint, as part of meeting his ITI requirements. Should he consider other technologies he had seen, such as audience response systems (or “clickers", as they were commonly known)?

In addition to content specific questions, Kissi also wondered about the process of getting things started. He already knew Patterson, head of the MIT, and felt free to set up a meeting with him at any time. He was also aware, however, that the MIT always had many projects going on. What types of preparation would he need to do in order to make the projects for his classes irresistible to them? Should he approach them with a very specific set of requirements he'd like to see fulfilled and a clear vision of what the end product would look like? That would certainly make their job more straightforward. Or would it be better to approach them with a general objective, such as one of those previously listed, and let them help him translate his needs into a solution? That would allow them to apply their knowledge and design skills to the problem. Or should he just lay out his current courses in front of them and ask them to come up with ideas? That would certainly offer them the greatest opportunity for creativity. But it also sounded a bit like a process that could take decades to complete-if it ever reached completion.

No matter how he approached MIT, Kissi recognized that any large project that was proposed would have to compete with many other projects for resources. He believed, however, that finding new ways to help his students learn more effectively offered a big payback. 


\section{Exhibit 1: USF Africana Studies Mission}

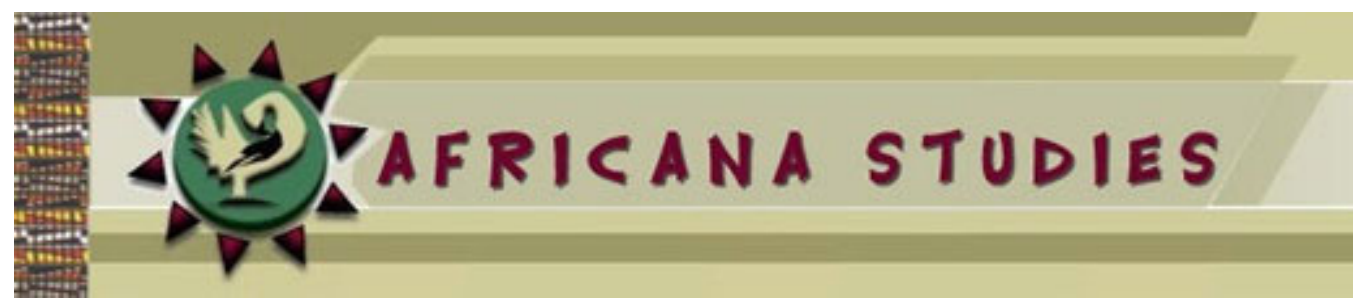

\section{Academic Mission}

Our academic mission and curriculum are rooted in the history and traditions of Africana Studies, but dynamic enough to recognize new trends in the discipline, the academic objectives of the University of South Florida, our society and changing needs of the wider world.

We recognize Africana Studies as a liberal arts program of education that takes an interdisciplinary approach to the study of the history and experiences of the continent of Africa and people of African descent dispersed across the glove. But given our current faculty strength, the curriculum of the Department of Africana Studies emphasizes the history and experiences of Africans in West, East and Central Africa, the United States (with particular emphasis on Florida), the Caribbean, and Latin America. The Department of Africana Studies acknowledges that the African and African Diaspora experiences are part of the history of the wider world and that that history is best understood from a humanistic perspective that is, at once, global and comparative. Integral to this global and comparative Diaspora orientation is also our recognition of the importance of transnational, but also local and community issues such as race, culture, gender, political economy, and public health. We believe that mastery of these issues in our undergraduate and graduate programs will prepare our students to be effective social and historical agents in a diverse, complex and changing world.

1. Consequently, the academic mission of the Department of Africana Studies compasses the following: To provide undergraduate and graduate students with a program of interdisciplinary studies on African and African Diaspora experiences.

2. To engage students in comparative research on the history and culture of continental and Diaspora Africans

3. To provide students with knowledge and skills relevant to community issues and development, with emphasis on Florida localities

4. To facilitate student appreciation of the role of indigenous knowledge in the organization of human societies

5. To provide the forum in which students can explore the concept of race; the means by which racism is institutionalized in such human organizational contexts as education, government, the economy, and the media, as well as the relationship between racial prejudice and the physical and mental health of Africans in the Diaspora.

6. To train students and equip them with all the tools of a liberal arts education: ability to develop and/or refine critical thinking, analytical, oral and written communication skills.

Source: USF Africana Studies web site (http://www.cas.usf.edu/africana_studies/mission.html) accessed on $4 / 22 / 06$. 


\title{
Exhibit 2: Syllabus Excerpts
}

\author{
University of South Florida, Tampa. \\ AFH 3200-001: AFRICAN HISTORY SINCE 1850 \\ Spring: 2006. T.R., 3:30-4:45pm. Rm. EDU 347.
}

Edward Kissi.

FA0 265. E-mail: ekissi@cas.usf.edu.

Office Hours: M.W. 10:00am-12:00 pm. Tel.: 974-7784.

Course Materials: [Required and Highly Recommended Books are available for purchase at Books for Thought Bookstore. 10910 North 56th Street. Tampa, FL. Or call Felicia Wynten at 988-6363].

Required Books :

1. Kevin Shillington. History of Africa. Revised $2^{\text {nd }}$ Edition. New York: Palgrave Macmillan, 2005. Chapters 21 to 30.

2. Toyin Falola, ed. Africa. Volume 5: Contemporary Africa. Durham, NC.: Carolina Academic Press, 2003. Introduction, and Chapters 1, 6, 8, 9, 11, 17, 18, 19, $20,24$.

[Students are encouraged to do "internet research" and/or read other materials to adequately inform themselves about what has happened on the African continent recently (since 2000).]

Web resources:

http://www.su1.stanford.edu/depts/ssrg/africa/history.html.

http://www.bbc.co.uk/worldservice/africa/features/storyofafrica/index.shtml .

http://www.utexas.edu/conferencesafrica.

Highly Recommended, But Not Required:

1. Roland Oliver and Anthony Atmore. Africa Since 1800 . Fifth Edition. Cambridge: Cambridge University Press, 2005.

2. Paul Nugent. Africa Since Independence. New York: Palgrave Macmillan, 2004. 


\section{Course Description:}

In a course covering nearly 156 years of the history of a huge and diverse continent larger than a combination of the entire United States, all of China and India, and the whole continent of Australia, choices must necessarily be made about what to study and how to study them. Therefore, rather than undertake, in one academic semester, the tough and impossible task of studying the history of every region of the continent since 1850, the course will provide some answers to two important questions and the debates they generate.

1. Why did Africans fail to prevent European colonization of their societies after 1850? An adequate answer to this question would require a discussion of the state of the continent in 1850, the convergence of factors that made colonization possible and the motives behind the European partition of Africa into colonies. This should help us to draw some important conclusions about whether European colonization of Africa was beneficial to the Africans, as some scholars argue, or detrimental to them, as others suggest.

2. What have Africans done for themselves and their continent since the end of colonial rule, and how can their successes and failures be measured? This question should lead us to examine African reactions to colonial rule, the struggle for independence and the achievements and failures of nation-building in post-colonial Africa. Ultimately, an examination of this second question should help us to make some definitive conclusions about whether the problems that some independent African nation-states have encountered since the end of colonial rule were the product of destructive human tendencies in Africa itself or the consequences of external and other natural factors beyond the control of Africans.

The above approach allows us to focus on some of the major themes, topics and/or events and debates in African history since 1850; compare the experiences of different colonial and postcolonial societies on the continent and place them in the context of global developments since 1850.

Attendance in class is mandatory because lectures and class discussions will cover relevant ideas and debates on African history since 1850 that may not exist in the assigned course materials.

\section{Course Objectives:}

This course is intended to inform and to inspire. So at the end of the course students who enrolled in it, and took the course seriously, would have learned the following:

1. Some of the most important events in Africa since $\mathbf{1 8 5 0}$ and the various ways in which scholars who have studied those events have explained them.

2. To look at many and sometimes contradictory historical evidence or information about Africa and interpret those evidence in a manner that is accurate and persuasive and in a way that allows students to reach their own conclusions about what has happened on the African continent since 1850.

3. To develop a passion for reading a wide range of historical material and communicating ideas in a clear and coherent manner.

4. To think seriously about how to measure "success"; "development" ; "progress" and "failure" in the history of people and nations in Africa and the roles that human, natural, internal and external factors play in that history. 


\section{EXPECTATIONS OR WHAT IS REQUIRED TO GET A GOOD GRADE IN THIS COURSE.}

(1). Come to class regularly. If you are unable to attend a particular class because of a religious holiday or some other reason, send the professor an e-mail or call him by phone to explain why you would be absent from class. Bring a physician's report or note to back up an excuse for missing a class on medical grounds. If you miss a class, go and talk to the professor during his office hours so that he can go over the materials or lectures you missed with you. This is important!

(2). The professor is aware that this is not the only course you are taking at USF. However, to do well in this particular course, you will need to read all required course materials. The specific chapters or pages of course materials that appear under the list of topics in this course outline as "required readings" are the places where students can find information and other ideas about the topics. Students are encouraged to read all the assigned chapters on topics or some of them in order to be able to follow the professor's lectures on a particular topic and participate actively in class discussions on it. Every student should have completed the assigned reading before class discussions on a topic. Note that not everything in an assigned chapter is relevant to a topic. As you read, look for information or take notes on ideas that are relevant to the topic under discussion. Send an e-mail to the professor or call him by phone to lodge any complaint you have about the course, seek clarification on a lecture in class or difficult issues in the assigned readings and other course materials.

(3). Many students argue, quite correctly, that too much lecturing or talking by a professor in a class makes a course boring. Therefore, this course has class discussions as a key component. As a student in this course, you have an equally important role to play in making the class exciting and the investment of your money and time in this course rewarding. So come to class ready and prepared to participate in class discussions. Shyness or lack of preparedness will not be an excuse for non-participation. The classroom is a place of learning so do not be afraid to ask questions, share your ideas or participate in group discussions in class.

(4). The professor is fully aware that this is a history course and not a course on English Composition. But he recognizes that it is through the English language that he and students can communicate their thoughts and ideas on the course. Therefore, clear and coherent expression of ideas will be very important factors in the grading of student papers and examinations in the course. All written examinations would test the extent of your understanding of both lectures and course materials. The professor expects students who want very good grades in this course to demonstrate an ability to communicate very good information or persuasive ideas in clear and coherent language. There will be no make up examination in this course. 
Course Schedule and Required Readings

Jan. 10: Explaining course objectives, requirements, class tests, grading system and general conversation with students about Africa.

\section{Jan. 12, 17, 19: AFRICA IN 1850 AND THE EUROPEAN PARTITION OF THE CONTINENT INTO COLONIAL SPHERES OF INFLUENCE.}

\section{Required readings:}

Shillington. Chs. 21 and 22.

Jan. 12: Lecture on basic facts about Africa and the state of the continent between 1850 and 1884.

Jan. 17: Lecture explores the European partition of Africa into colonial spheres of influence, after 1884, and the debate among scholars about European interests in Africa at this period.

JAN. 19: Questions and in-class group discussion on period and issues covered.

Question to think about: Was Africa in dire need of European colonialism and/or "guardianship"?

\section{Jan. 24, 26, 31: EUROPEAN COLONIAL POLICIES AND THEIR EFFECTS ON AFRICA.}

Required readings:

Shillington. Chs. 23 and 24.

Falola. Ch. 1.

Jan. 24: Lecture examines European colonial policies in Africa and the debate among scholars about the impact of those policies on African societies.

JAN. 26 and JAN. 31: Questions and in-class group discussion.

Questions to think about: Did colonialism change Africa "forever"?. Did it "develop"; "modernize" or "under-develop" and "weaken" Africa? How should we explain or interpret the "colonial period" in African history? 
III. Feb. 2, 7, 9: AFRICAN RESISTANCE TO COLONIAL RULE AND THE STRUGGLE FOR INDEPENDENCE.

Required readings:

Shillington. Chs. 24, 25, 26, 27.

Falola. Ch. 9.

Feb. 2: Lecture looks at the nature and purpose of African resistance to colonial rule before World War II, and the process and politics of decolonization in Africa.

FEB. 7 and 9.: Questions and in-class group discussions.

Key questions to think about:

1. Was decolonization or independence a product of African nationalism or European goodwill?

2. Did "independence" set post-colonial African nation-states on the road to "development", "success" or "failure"? Was it a "cup of plenty" or "poisoned chalice"?

\section{FEB. 14. FIRST CLASS TEST [20\%].}

\section{NO MULTIPLE CHOICE QUESTIONS IANSWERS.}

There will be SIX questions, each carrying FIVE points or marks, in the class test. You will be required to answer all of them. Answers should be written on the test paper in the spaces below the questions. All answers should be brief, straightforward and easy to read. NOTE THAT YOU WILL NOT BE GIVEN THE TEST QUESTIONS AHEAD OF TIME. The in-class test has two important objectives. First, to find out how well students have read the textbooks, understood lectures and other course materials. Second, to find out how well students can write, summarise or formulate ideas in a brief, clear and coherent manner.

Sample question:

According to Adu Boahen, Africa was in a state of positive transformation between 1850 and 1880 , i.e. before formal European colonization of the continent. Briefly describe some of the political and economic changes in Africa at this period.

IV. Feb. 16, 21, 23: POLITICS AND ECONOMIC DEVELOPMENT STRATEGIES IN POSTCOLONIAL AFRICA.

Required readings: 
Shillington. Ch.28.

Falola. Introduction. Chs. 8, and 18.

FEB. 21 and 23.: Questions and in-class group discussion on the legacies of colonial rule; potentials for "development" and problems affecting some post-colonial African nation-states.

STUDENTS SHOULD COME UP WITH THEIR OWN DEFINITIONS OF "DEVELOPMENT" OR WHAT, IN THEIR VIEW, CONSTITUTED "SUCCESSFUL DEVELOPMENT" IN AFRICA IN THE EARLY POST-COLONIAL PERIOD. 
V. Feb. 28, Mar. 2, 7: AFRICA AND THE GLOBAL ENVIRONMENT: THE COLD WAR AND ITS IMPACT ON AFRICAN POLITICS AND INTERNATIONAL RELATIONS.

\section{Required readings:}

Shillington. Ch. 28.

Falola. Chs. 1, 11 and 17.

MAR. 2, 7: Questions and in-class group discussions on the effects of U.S. Cold War policy on nation-building in some independent African nation-states.

MAR. 9: SECOND CLASS TEST [20\%].

Class test will follow the same pattern as in first class test.

SPRING BREAK: MARCH 13-18.

VI. Mar. 21, 23, 28: DEBT ACCUMULATION, WAR AND FAMINES IN AFRICA

Required readings:

Shillington. Ch. 29, 30.

Falola. Ch. 19, 20, 24.

Recommended, But Not Required

Edward Kissi, "Beneath International Famine Relief in Ethiopia: The United States, Ethiopia, and the Debate over Relief Aid, Development Assistance, and Human Rights." African Studies Review, vol. 48, no. 2 (Sept. 2005):111-32.

MAR. 23, 28: Questions and in-class group discussion on the root-causes of debt, wars and famines in Africa and their impact on African life.

VII. Mar. 30, Apr. 4, 6: AFRICA IN THE GLOBAL ECONOMY: INTERNATIONAL TRADE, AID AND DEBT REPAYMENTS.

\section{$\underline{\text { Required readings: }}$}

Shillington. Ch.29.

Falola. Ch. 24.

APR. 4, 6: Questions and in-class group discussion on the uses and abuses of aid in Africa and the effects of the global economy on the lives of people on the continent. 


\section{APR. 11.: THIRD CLASS TEST [20\%].}

Class test will follow the same pattern as in first class test.

VIII. Apr. 13, 18, 20: PUBLIC HEALTH IN AFRICA: MEDICAL CARE AND THE AIDS PANDEMIC.

Required readings:

Shillington. Ch. 30.

Falola. Chs. 6.

APR. 18, 20: Questions and in-class group discussion on HIVIAIDS in Africa: causes, effects and solutions.

IX. Apr. 25, 27.: IN-CLASS GROUP DISCUSSION ON MEASURING "SUCCESS" AND "FAILURE" IN AFRICAN HISTORY SINCE 1850.

Required readings:

Falola. Introduction.

Shillington. Ch. 30.

Questions:

Have Africans Done Much and/or Enough for Themselves?

How should students and scholars measure "success" and "failure" in their analyses of African history since 1850 ?

Students are encouraged to think about and suggest policies and programs that can address problems in Africa, if any, and/or "sustain" progress, if any.

Apr. 29-May 5: FINAL EXAM. WEEK. FINAL EXAM: [20\%].

For the final examination in this course, students would be required to use notes taken from class lectures and discussions to write a clear, coherent and persuasive essay on ONLY ONE of the following questions:

1. What are the most important events that have occurred on the African continent since 1850 and how have they affected the lives of people in Africa? 
2. How should students and scholars who study African history measure or evaluate the success and failure of Africans in their nation-building efforts since the end of colonial rule?

This essay should not exceed three typed and double-spaced pages. It would be evaluated on its content, breadth of evidence presented, clarity of interpretation of evidence and the quality of conclusions reached.

THE ESSAYS SHOULD BE GIVEN DIRECTLY TO THE PROFESSOR IN HIS OFFICE ON OR BEFORE FRIDAY MAY 5, 2006. 


\section{Biographies}
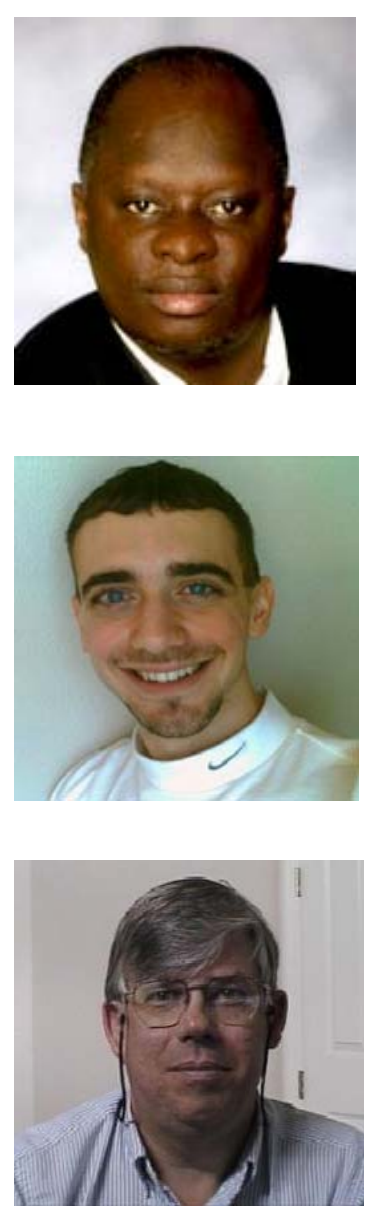
undergraduate and graduate students.

Edward Kissi is an Assistant Professor in the Africana Studies department at the University of South Florida. He received his $\mathrm{PhD}$ in History from Concordia University in Montreal, Quebec. He also holds a Masters degree from Wilfrid Laurier University and an undergraduate degree from the University of Ghana. His principal research focus is the study of genocide. In addition to many refereed articles, book chapters and scholarly presentations on the subject, he recently published a book titled "Revolution and Genocide in Ethiopia and Cambodia" with Lexington Books. He currently teaches undergraduate courses on African History, the Black Experience and on Genocide.

Chris Lettre is a Dual Master's student at the University of South Florida. He is pursuing a Master's in Management Information Systems and a Master's in Business Administration. In 2005, he graduated Magna Cum Laude with a Bachelor's in Management Information Systems from the Honors program at the University of South Florida. In addition, he works as the Technical Director for a professional staffing agency.

Grandon Gill is an Associate Professor in the Information Systems and Decision Sciences department at the University of South Florida. He holds a doctorate in Management Information Systems from Harvard Business School, where he also received his M.B.A. His principal research focus is in the area of IS education, and he has published many articles describing how technologies and innovative pedagogies can be combined to increase the effectiveness of teaching across a broad range of IS topics. Currently, he teaches programming, database and managerial courses to both 